\title{
Technical Note: Measuring moisture content of small seeds
}

\author{
D. TERRANCE BOOTH AND YUGUANG BAI
}

Authors are rangeland scientist., USDA-ARS, High Plains Grassl. Res. Sta., 8408 Hildreth Road, Cheyenne, Wyo. 82009; and research scientist, Dept. of Plant, Soil and Insect Sci., Univ. of Wyoming, Laramie, Wyo. 82071. Present address of Bai: Kamloops Range Res. Station, Ag. and Agri-Food Canada, Kamloops, BC V2B $8 A 9$ Canada.

\begin{abstract}
An accurate determination of moisture content in hydrated or partially hydrated seeds is fundamental to understanding early physiological processes in seeds, and the associated environmental interactions that affect seedling vigor, establishment, and survival. One difficulty encountered while measuring the moisture content of imbibed seeds is that water evaporates from the seed during weighing. This is particularly significant for small seeds because they have a large surface area to volume ratio. We developed a procedure using a standard tin capsule and microbalance which was simple, inexpensive, facilitated precise measurement of moisture in hydrated seeds, and provided reliable results with a minimal amount of seeds. The method is recommended as a means for increasing the accuracy of seed weight and seed moisture measurements.
\end{abstract}

Key Words: sagebrush, Artemisia tridentata ssp. wyomingensis, analytical balance, tin capsule

Moisture content is a key variable in most investigations of the physiology of seed germination and early seedling growth. Accurate, consistent methods are needed to measure this variable.

Among the many methods of determining seed moisture, oven drying is most commonly used because it is economical, requires simple equipment and little technical expertise, and can be used with any kind of seeds at any moisture content (Grabe 1989). However, water evaporation from high-moisture seeds during weighing can reduce measurement accuracy. This is an especially important consideration for small seeds because they have a large surface area to volume ratio. Also, measuring seed weight for small seeds may require large numbers of seeds. This may be a problem where seed is expensive, difficult to collect, or where seeds are to be obtained from previous treatments.

To overcome the evaporation problem, researchers have made containers from aluminum foil, have used plastic microfuge vials (Welbaum, personal communication), or have used aluminum volatile sample pans designed for Differential Scanning Calorimetry (Pammenter et al. 1991). Plastic will volatilize and is not suitable for use in drying ovens where the container must

Mention of trade or company names is for information only and does not imply an endorsement.

Authors thank Drs. Susana Goggi, Don Grabe, Jack Peters and Gregory Welbaum for reviewing this manuscript and Ms. D. Xiang for computer assistance. Manuscript Manuscript accepted 4 Apr. 1997. maintain constant weight. The labor for making containers from aluminum foil and the use of volatile sample pans are both expensive. Therefore, we developed a procedure to measure seed moisture of small seeds using a standard tin capsule and microbalance. We used seeds of Wyoming big sagebrush (Artemisia tridentata Nutt. ssp. wyomingensis Beetle \& Young), though any small seed that would fit inside the capsule could have been used. Wyoming big sagebrush seeds have 4.0 to 5.4 million seeds per $\mathrm{kg}$ (Meyer, in press).

\section{Materials, Methods, and Results}

\section{Description of capsules}

The tin capsule we tested is manufactured by LECO Corporation (St. Joseph, Mich. 49085, part No. 501-059) and sells for about $\$ 36$ per package of 100 . LECO capsules are designed to hold powder or liquid samples by crimping the open end of the capsule before analysis of the sample for $\mathrm{C}, \mathrm{H}, \mathrm{N}, \mathrm{S}$, or $O$. The standard capsule has a mean weight \pm standard error (SE) of $179.040 \pm 2.150 \mathrm{mg}$, and a volume of $0.25 \mathrm{ml}$. Other capsule sizes are available.

\section{Description and operation of the balance}

Weighing was done with a CAHN C-32 microbalance (CAHN Instruments, Inc., Cerritos, Calif. 90701). This microbalance measures to $0.0001 \mathrm{mg}$ and the range we used was $0.001 \mathrm{mg}$. An EIA standard RS232C interface was used to connect the balance to an IBM286 personal computer. A BASIC software program, enclosed with the owners manual, was modified for our use and allowed data to be stored in a spreadsheet or printed through a printer. Measurement accuracy is influenced by operation of the balance. We allowed at least 2 hours of warm up as suggested by the owner's manual. After a sample was placed on the balance, an average of 1.26 minutes (results of 10 measurements with a minimum of 1.02 and a maximum of 1.43 minutes) was needed for the balance to stabilize and transmit data to the printer. We used 1.5 minutes per measurement for all weighing in this experiment. One capsule was repeatedly weighed 10 times to determine the variation of the balance. Resulting data had a standard deviation (SD) and a SE less than $0.001 \mathrm{mg}$.

\section{Capsule weight change after oven drying}

Ten capsules were weighed and then dried at $80^{\circ} \mathrm{C}$ for 24 hour, then reweighed. The mean weight change of capsules after oven drying was less than $0.001 \mathrm{mg}$, with a SD of $0.003 \mathrm{mg}$ and a SE 
of $0.001 \mathrm{mg}$, which was similar to the variation of the balance. Therefore, the tin capsules did not change weight after conventional oven drying.

\section{Sealing efficiency of capsules}

Open and closed capsules, each containing 20 sagebrush seeds, were placed above distilled water in a closed plastic box at $10^{\circ} \mathrm{C}$. The open end of sealed capsules had been folded twice and crimped with tweezers. The sealing process took approximately 3 seconds per capsule. Capsules were retrieved after 0, 2, 4, 6, 8, $16,24,48,120$, and 360 hours. Open capsules were sealed immediately after retrieval as described above. Samples were weighed approximately 30 minutes after retrieval as well as after 24 hours of oven drying at $80^{\circ} \mathrm{C}$. Capsules were opened during oven drying and re-sealed after removal from the oven. Four replications were used for each treatment.

The moisture content of seeds in open capsules increased rapidly after humidification (Table 1). Seeds in sealed capsules did not absorb significant amounts of water in the first 5 days, but the moisture content did increase after 15 days.

\section{Effect of balance precision on the determination of mois- ture content}

We used a microbalance with the precision set at $0.001 \mathrm{mg}$ as described above. Weight data were rounded up to $0.01,0.1$, and 1 $\mathrm{mg}$ to test the effect of assumed accuracy on seed moisture determination (Table 1). After data were rounded up to $0.01 \mathrm{mg}$, changes in the moisture content results were less than $0.2 \%$; rounding up to $0.1 \mathrm{mg}$ resulted in changes between $0.1-0.9 \%$. Dramatic changes in seed moisture were found when data were rounded up to $1 \mathrm{mg}$, and the difference could be as high as $14 \%$.

Table 1. Moisture content (mean \pm SE, d.wt.) of sagebrush seeds in sealed and open capsules after various humidification durations at $10^{\circ} \mathrm{C}$. Data for seeds in open capsules were rounded-up to $0.01,0.1$, or $1 \mathrm{mg}$ for comparison among assumed balance precision. The first 2 columns of moisture data are from Bai et al. 1997.

\begin{tabular}{|c|c|c|c|c|c|}
\hline \multicolumn{3}{|c|}{ Sealed capsule } & \multicolumn{2}{|c|}{ Open capsule } & \multirow[b]{3}{*}{$1 \mathrm{mg}$} \\
\hline Humidifi & tion & & & & \\
\hline duration & $0.001 \mathrm{mg}$ & $0.001 \mathrm{mg}$ & $0.01 \mathrm{mg}$ & $0.1 \mathrm{mg}$ & \\
\hline \multicolumn{6}{|l|}{ (hours) } \\
\hline & \multicolumn{5}{|c|}{$-\ldots(\%)$} \\
\hline 0 & $4.6 \pm 0.5$ & $4.5 \pm 0.4$ & $4.5 \pm 0.4$ & $4.6 \pm 0.8$ & $8.3 \pm 8.3$ \\
\hline 2 & $4.2 \pm 1.0$ & $10.7 \pm 1.1$ & $10.7 \pm 1.1$ & $11.3 \pm 1.0$ & $6.3 \pm 6.3$ \\
\hline 4 & $4.3 \pm 0.9$ & $14.4 \pm 1.2$ & $14.5 \pm 1.2$ & $14.7 \pm 1.1$ & $12.5 \pm 7.2$ \\
\hline 6 & $4.5 \pm 0.6$ & $17.3 \pm 0.9$ & $17.4 \pm 0.9$ & $17.6 \pm 1.4$ & $23.8 \pm 1.3$ \\
\hline 8 & $48 \pm 1.0$ & $18.3 \pm 0.8$ & $18.3 \pm 0.8$ & $18.1 \pm 1.2$ & $23.8 \pm 1.3$ \\
\hline 16 & $5.1 \pm 0.8$ & $31.4 \pm 2.5$ & $31.5 \pm 2.5$ & $31.6 \pm 2.6$ & $30.0 \pm 6.8$ \\
\hline 24 & $5.5 \pm 0.5$ & $36.1 \pm 3.6$ & $36.2 \pm 3.6$ & $36.7 \pm 3.9$ & $39.2 \pm 11$ \\
\hline 48 & $5.8 \pm 1.0$ & $41.6 \pm 1.5$ & $41.6 \pm 1.5$ & $41.9 \pm 1.5$ & $37.5 \pm 7.2$ \\
\hline 120 & $7.2 \pm 1.1$ & $58.1 \pm 6.5$ & $57.9 \pm 6.5$ & $57.2 \pm 6.7$ & $71.3 \pm 11$ \\
\hline 360 & $16.5 \pm 5.9$ & $60.7 \pm 2.3$ & $60.7 \pm 2.4$ & $61.2 \pm 3.0$ & $56.3 \pm 6.3$ \\
\hline
\end{tabular}

\section{Discussion and Conclusion}

We detected no change in capsule weight due to oven drying, and no change in the moisture content of sagebrush seeds sealed in these capsules over 5 days of humidification. Water evaporation from hydrated seeds during handling or weighing is our concern. Weighing takes just a few minutes; therefore, sealing hydrated seeds in tin capsules will prevent evaporation from seeds during handling. The aluminum volatile sample pans (Perkin-Elmer part No. 0219-0062) used for this purpose have an effective volume of $20 \mathrm{ml}$. A crimping tool, called the volatile sample sealer accessory (Perkin-Elmer part No. 0219-0061), is needed for sealing the pans. The pans cost about 3 times that of standard tin capsules, and the crimping tool sells for about $\$ 1,000$. We measured the time needed to seal capsules and pans, and found it took less time to seal capsules.

The precision required in a balance will depend on seed size and the number of seeds. We used 20 sagebrush seeds per sample, and the precision at $0.001,0.01$ and $0.1 \mathrm{mg}$ was acceptable, but not at $1 \mathrm{mg}$. A microbalance with a precision of $0.001 \mathrm{mg}$ may require up to $1.5 \mathrm{~min}$ for stable readings, while one with a precision of $0.1 \mathrm{mg}$ may require just 5 seconds. Therefore, depending on the seed size and number, the number of samples, and the requirements of researchers, a less precise balance (which costs much less than the microbalance we used) may also produce meaningful results while saving weighing time.

In conclusion, we recommend the use of tin capsules, similar to the ones used in this study, for obtaining accurate weights of hydrated seeds. Combining use of capsules with appropriate microbalance technique allows accurate measurement of moisture for small seeds. The method is simple, inexpensive and can be used for seed samples in the field and the laboratory.

\section{Literature Cited}

Bai, Y., D.T. Booth, and E.E. Roos. 1997. Effect of seed moisture on Wyoming big sagebrush seed quality. J. Range Manage. 50:419-422.

Grabe, D.F. 1989. Measurement of seed moisture. pp 69-92. P.C. Stanwood and M.B. McDonald (eds.). Seed moisture. Special Pub. No. 14. Crop Sci. Soc. Amer. Madison, Wisc.

Pammenter, N.W., C.W. Vertucci, and P. Berjak. 1991. Homeohydrous (Recalcitrant) seeds: Dehydration, the state of water and viability characteristics in Landolphia kirkii. Plant Physiol. 96:1093-1098.

Meyer, S.E. Artemisia. In: F. Bonner (ed). Seeds of Woody Plants of the United States-Revised. USDA, Forest Serv. (In press). 